\title{
The New Pact and EU Agencies: A Tale of Two Tracks of Administrative Integration and Unsatisfactory Embedding
}

\author{
Evangelia (Lilian) Tsourdi"
}

The 'New Pact on Migration and Asylum', ${ }^{1}$ and the relevant legislative proposals that accompany it, adopt an ambivalent approach towards administrative integration. They partly recognise EU agencies' increased involvement in the implementation of EU's migration, asylum, and external border control policies. At the same time, they do not satisfactorily embed the novel functions of EU agencies, such as their increased executive powers. This means that, for example, new procedural steps introduced by the Pact such as the screening at the external borders ${ }^{2}$ or the border procedure, ${ }^{3}$ neither take to account the particularities of the potential involvement of EU agencies in these processes nor do they frame these executive powers. This could have a potential impact on migrants' procedural rights and on the accountability of EU agencies. In addition, the Pact ingrains a two-track approach to administrative integration. Alongside institutionalised administrative cooperation through EU agencies, the Pact emphasizes bilateral and multilateral transnational cooperation between Member States, as portrayed by the new concept of return sponsorships. ${ }^{4}$

Assistant Professor and Dutch Research Council (NWO) grantee, University of Maastricht, Faculty of Law and Maastricht Centre for European Law. This work was supported by a VENI programme grant (project Nr. VI.Veni.191R.040) which is financed by the Dutch Research Council (NWO). The author would like to thank Daniel Thym for insightful comments in a previous version. All errors remain my own.

1 Commission Communication on a New Pact on Migration and Asylum, $\operatorname{COM}(2020) 609$ of 23 September 2020 ('Pact Communication').

2 Commission Proposal for a Regulation introducing a screening of third country nationals at the external borders, $\operatorname{COM}(2020) 612$ of 23 September 2020 ('Screening Regulation Proposal').

3 Amended Proposal for a Regulation establishing a common procedure for international protection in the Union and repealing Directive 2013/32/EU, COM(2020) 611 of 23 September 2020 ('Amended Proposal for an Asylum Procedures Regulation').

4 Proposal for a Regulation of the European Parliament and the Council on asylum and migration management and amending Council Directive concerning the sta- 
This could potentially impact the effectiveness of administrative cooperation and migrants' fundamental rights protection.

This article, first, analyses in greater detail which are the two tracks of administrative integration, and briefly outlines the novel functions that two EU agencies, FRONTEX (used as a shorthand for the EU's European Border and Coast Guard Agency), ${ }^{5}$ and EASO (used as a shorthand for the EU's European Asylum Support Office), ${ }^{6}$ undertake in these fields. Next, I explain which legal instruments are to regulate their mandate according to the Pact, and whether the Commission Communication on the Pact contains novelties regarding their role. Finally, I draw examples from two Pact legal instruments, notably the Proposal for an Asylum and Migration Management Regulation and the Amended Proposal for an Asylum Procedures Regulation to illustrate the Pact's ambivalent approach to administrative integration.

\section{The Two Tracks of Administrative Cooperation and EU Agencies' Novel}

\section{Functions}

Administrative cooperation in the EU external border control, migration, and asylum policies has been pursued through two tracks. The first track is bilateral and multilateral transnational cooperation between Member States. The second track is institutionalised practical cooperation through EU agencies which has gradually evolved to joint implementation patterns and increased administrative integration. It is important to understand what each track entails to critically analyse a crucial development under the Pact, which is a renewed attention towards the first track of administrative cooperation.

In what concerns the first track, informal information-exchange among Member States, for example on asylum, started as early as 1992 through a consultation group chaired by the Council called CIREA (Centre for In-

tus of third-country nationals who are long-term residents, $\operatorname{COM}(2020) 610$ of 23 September 2020 ('Proposal for an Asylum and Migration Management Regulation').

5 Regulation (EU) 2019/1896 of the European Parliament and of the Council of 13 November 2019 on the European Border and Coast Guard and repealing Regulations (EU) No 1052/2013 and (EU) 2016/1624, OJ L 295/1 ('2019 EBCG Regulation').

6 Regulation (EU) 439/2010 of the European Parliament and of the Council of 19 May 2010 establishing a European Asylum Support Office ('EASO Regulation'). 
formation, Discussion and Exchange on Asylum). While its aim was facilitating coordination of practice, results were limited and the Commission lamented its ineffectiveness. ${ }^{7}$ Apart from information exchange through administrative networks, Member States sought transnational cooperation through ad hoc projects. For example, in 2004 the Dutch Presidency established of annual exchanges between General Directors of European Immigration Services (GDISC). Several projects supported by EU co-financing were developed under the auspices of GDISC. One such project was the European Asylum Curriculum (EAC), originally developed by a group of Member States led by Sweden with the financial support of the European Commission, and in cooperation with the Odysseus Academic Network. Its main aim was to 'create a learning tool for the advancement of both knowledge and skills among officials working with asylum issues' ${ }^{8}$ Nonetheless, it soon became apparent that ad hoc projects, and loose networks of information exchange were not enough to effectively address the implementation gap in EU's asylum, external border control and return policies. This led to the emergence of institutionalised administrative cooperation, and EU agencies.

The second track has been characterised by institutionalisation, and the creation of relevant EU agencies. This development came about later chronologically. The FRONTEX Regulation has undergone a series of legislative amendments since member states adopting the agency's founding document in 2004. ${ }^{9}$ Notably, the instrument was amended consecutively

7 Commission Communication Towards a common asylum procedure and a uniform status, valid throughout the Union, for persons granted asylum, $\operatorname{COM}(2020) 755$ of 22 November 2020.

8 European Asylum Curriculum, 'A Vocational Training Program for the Asylum Process in Europe Objectives and Content', $6<$ www.temaasyl.se/Documents/Progr am/ARGO/European\%20Asylum\%20Curriculum.pdf $>$ accessed 1 December 2021.

9 Council Regulation (EC) No 2007/2004 of 26 October 2004 establishing a European Agency for the Management of Operational Cooperation at the External Borders of the Member States of the European Union, OJ L 349/1. 
in $2007,{ }^{10} 2011,{ }^{11} 2016,{ }^{12}$ and most recently in November $2019^{13}$ - the legal document which is currently in force. EASO was set up in $2010,{ }^{14}$ and an agreement on an updated legal mandate was only reached in the course of $2021 ; ;^{15}$ its role has shifted de facto though. I analyse these developments and the status quo on EASO's legal mandate in detail below. Overall, much has changed since these agencies were initially set up. Institutionalization of practical cooperation through EU agencies has begun to unsettle the initial implementation paradigm of 'the EU legislating' and 'Member States implementing'.

Focusing specifically on the de jure and de facto mandate expansion of EASO and FRONTEX two broad trends become apparent:

On the one hand, the operational expansion of EU agencies' mandates has led to patterns of joint implementation, ${ }^{16}$ with their staff and experts deployed in fields such as border control, returns and the processing of asylum claims. This means that agency deployees increasingly have executive powers, implement policy alongside national authorities and administrations, and directly interact with refugees and migrants. On the other hand, these agencies' mandate has expanded to encompass functions that far exceed support, including operational support and administrative coop-

10 Regulation (EC) No 863/2007 of the European Parliament and of the Council of 11 July 2007 establishing a mechanism for the creation of Rapid Border Intervention Teams and amending Council Regulation (EC) No 2007/2004 as regards that mechanism and regulating the tasks and powers of guest officers, OJ L 199/30 ('2007 FRONTEX Regulation').

11 Regulation (EU) No 1168/2011 of the European Parliament and of the Council of 25 October 2011 amending Council Regulation (EC) No 2007/2004 establishing a European Agency for the Management of Operational Cooperation at the External Borders of the Member States of the European Union, OJ L 304/1.

12 Regulation (EU) 2016/1624 of the European Parliament and of the Council of 14 September 2016 on the European Border and Coast Guard and amending Regulation (EU) 2016/399 of the European Parliament and of the Council and repealing Regulation (EC) No 863/2007 of the European Parliament and of the Council, Council Regulation (EC) No 2007/2004 and Council Decision 2005/267/EC, OJ L 251/1 ('2016 EBCG Regulation').

132019 EBCG Regulation (n 5).

14 EASO Regulation (n 6).

15 Regulation (EU) 2021/2303 of the European Parliament and of the Council of 15 December 2021 on the European Union Agency for Asylum and repealing Regulation (EU) No 439/2010, OJ L 468/1 ('EUAA Regulation').

16 Evangelia (Lilian) Tsourdi, 'Bottom-up Salvation? From Practical Cooperation Towards Joint Implementation Through the European Asylum Support Office' (2016) 1 European Papers 997-1031. 
eration. Reference is made to monitoring-like, ${ }^{17}$ as well as to functions which have the potential to steer policy implementation..$^{18}$

One example of a monitoring-like function is the 'vulnerability assessment' that FRONTEX undertakes. ${ }^{19}$ This relates to issues such as state resources and state preparedness to undertake external border controls. It could lead to recommendations; a binding decision of measures set out by its Management Board; or, in cases where the external borders require urgent action, a Council implementing act prescribing measures which become binding for the Member States. An example of a function which has the potential to steer policy implementation is envisaged as part of a new European Union Agency on Asylum, the successor of EASO. This would be the adoption of a 'common analysis' on the situation in specific countries of origin and the production on this basis of guidance notes to assist Member States in the assessment of relevant asylum applications. ${ }^{20}$

One might have expected that these trends would have intensified, or at least would have been fully reflected in the New Pact and its different legal instruments. Nevertheless, the picture which emerges is far more nuanced. I examine, next, the legal mandate of these agencies according to the Pact.

\section{EU Agencies' Legal Mandates and the Pact: Nothing New under the Sun?}

The New Pact package does not alter the legal mandates of EASO and FRONTEX. This means that in what concerns FRONTEX the November 2019 instrument continues to regulate its functioning. ${ }^{21}$ Consecutive amendments to this legal instrument mean that it is more attuned to the new administrative realities, clearly prescribes the newer functions of the agency, and sets out, at least on paper, improved fundamental rights guarantees. Things are more complicated in what concerns EASO. At the time of writing, a 2010 Regulation still underpinned its functioning, ${ }^{22}$ while a

17 Evangelia (Lilian) Tsourdi, 'Beyond the migration crisis: the evolving role of EU agencies in the administrative governance of the asylum and external border control policies' in Johannes Pollak and Peter Slominski (eds), The Role of EU Agencies in the Eurozone and Migration Crisis: Impact and Future Challenges (Palgrave Macmillan 2021) 175, 184-188.

18 Ibid, 188-191.

192019 EBCG Regulation (n 5), art 32.

20 EUAA Regulation (n 15), art 11.

212019 EBCG Regulation (n 5).

22 EASO Regulation (n 6). 
final interinstitutional agreement on a new regulation had been struck and had received the endorsement of the EP LIBE Committee, the EP plenary, and the Council. ${ }^{23}$ As I have analysed elsewhere, ${ }^{24}$ this instrument has, since some time, no longer been fully attuned to the new administrative realities, such as joint implementation patterns, and this heightens EASO's accountability challenge.

The Commission issued a proposal for a revamped EUAA (used as a shorthand for the European Union Agency on Asylum) in 2016. ${ }^{25}$ The two co-legislators, i.e. the Council and the European Parliament, reached a political agreement for several chapters of the EUAA proposal in late 2017, but some salient issues remained pending. ${ }^{26}$ In the meantime, the Commission released in 2018 an amended proposal containing only targeted amendments reinforcing the operational tasks of the EUAA. ${ }^{27}$ The Commission did not release a new, or consolidated, proposal on the EUAA as part of the Pact. Instead, it urged co-legislators to swiftly adopt, concluding negotiations by the end of 2020, the new Regulation on the EUAA based on the pre-existing proposals and interim political agreements I outlined above. ${ }^{28}$

This approach led to the following result: a relatively speedy conclusion of the negotiations in the summer of 2021 but with part of the new instrument remaining frozen through the inclusion of a 'sunrise clause'. ${ }^{29}$ This relates to the new functions the co-legislators foresee for the EUAA in combination with its increasingly pivotal role in implementing intra-EU solidarity. Notably, the EUAA Regulation foresees a novel monitoring function of 'the operational and technical application of the CEAS in order to prevent or identify possible shortcomings in the asylum and reception systems of Member States and to assess their capacity and

23 EUAA Regulation (n 15).

24 See analysis in Evangelia (Lilian) Tsourdi, 'Holding the European Asylum Support Office Accountable for its role in Asylum Decision-Making: Mission Impossible?' (2020) 21 German Law Journal, 506.

25 Commission Proposal for a Regulation of the European Parliament and of the Council on the European Union Agency for Asylum and Repealing Regulation (EU) 439/2010, COM (2016) 271 ('EUAA 2016 proposal').

26 The partial agreement was included as an Annex I to Council of the European Union, Doc. 10555/17, ('EUAA partial agreement').

27 Amended proposal for a Regulation of the European Parliament and of the Council on the European Union Agency for Asylum and repealing Regulation (EU) No 439/2010, COM(2018)633 ('EUAA 2018 amended proposal').

28 Pact Communication (n 1), 3, 10.

29 See EUAA Regulation (n 15), art 73. 
preparedness to manage situations of disproportionate pressure so as to enhance the efficiency of those systems' ${ }^{30}$ This exercise is linked with a gradation of measures ranging from recommendations of the Management Board, to the involvement of the European Commission, to the Council mandating agency deployments in the territory of a specific Member State through an implementing act. ${ }^{31}$

Despite the circumscribed language on the content of the monitoring exercise, the 'Med 5' group of countries in Council (Greece, Spain, Italy, Cyprus and Malta) would only endorse the final agreement with the addition of a 'sunrise clause'. ${ }^{32}$ According to this clause, the monitoring exercise will only commence in 2024 , and then only partly. ${ }^{33}$ The 'enforcement part' of the mechanism, i.e. the gradation of measures I outlined before, will only commence as and when an agreement will be reached on the successor of the Dublin system that will include concrete responsibility-sharing arrangements. This final agreement attests both to the salience of solidarity for the functioning of the CEAS and of the importance that Member States place on the functions of EU agencies.

As for the operational functions of the EUAA, the final agreement reflects better, but not fully, the agency's enhanced role on the ground. Its role in asylum processing is recognised but the related wording is very careful, namely that the EUAA will 'facilitate the examination by the competent national authorities of applications for international protection or provide those authorities with the necessary assistance in the procedure for international protection' ${ }^{34}$ This formulation still does not encapsulate operational activities that EASO is currently undertaking in Greece and which I analyse below, for example independently conducting part of the asylum processing (admissibility or merits) and emitting an advisory opinion as to the outcome of individual applications. This careful formulation again illustrates the political sensitivities surrounding the expanded functions of EU agencies and, in essence, the resistance of Member States to legally frame them effectively. Analysis in the next section confirms these trends in the Pact's legal instruments.

30 Ibid, art 14(1).

31 Ibid, art 15.

32 See Jacopo Barigazzi, 'EU at long last agrees on reform of asylum agency' (Politico Europe, 29 June 2021) <www.politico.eu/article/after-5-years-eu-finds-deal-to-launc h-asylum-agency/> accessed 1 December 2021.

33 See EUAA Regulation (n 15), art 73.

34 Ibid, art 16(2)(c), emphasis added. 


\section{The New Pact and EU Agencies: What Way Forward for Administrative} Cooperation?

Having ascertained the Pact's position on the legal mandate of EU agencies, I now turn to analyse more broadly the way forward on administrative cooperation envisaged by the Pact. Namely, I fully substantiate arguments that I raised before: that the Pact instruments do not satisfactorily embed the novel functions of EU agencies, such as their increased executive powers; and that the Pact ingrains a two-track approach to administrative integration.

\section{a) The Commission Communication: Proclaiming the Importance of EU} Agencies in Administrative Cooperation

Some indications on the Pact's approach towards administrative cooperation can be drawn from the relevant Commission Communication, a nonlegally binding document. ${ }^{35}$ I already mentioned that the document called for the swift adoption of the amended EU agency proposal. However, it also contains further elements on the envisaged role of EU agencies.

Firstly, the Communication explicitly links mutual trust with 'consistency in implementation, requiring enhanced monitoring and operational support by EU agencies'. ${ }^{36}$ This is quite a bold statement which seems to recognise EU agencies' increased role in implementation and, even, in monitoring. FRONTEX's 'vulnerability assessments' are lauded by the Commission as 'particularly important, assessing the readiness of Member States to face threats and challenges at the external borders and recommending specific remedial action to mitigate vulnerabilities'. ${ }^{37}$ These assessments allow to 'target the Agency's operational support to the Member States to best effect'. ${ }^{38}$ This means that structural shortcomings and capacity issues first identified through these supervision-like processes can then be (partially) overcome through the additional deployment of human and technical resources and enhancement of joint implementation actions.

Thereafter, the Communication outlines the importance of the envisaged monitoring mechanism as part of a new EUAA. This mechanism has

35 Pact Communication (n 1).

36 Ibid, 6.

37 Ibid, 12.

38 Ibid. 
been added to the EUAA mandate but will remain 'frozen' as analysed above; EASO does not currently hold such a function. Monitoring is explicitly linked with 'bringing greater convergence' and boosting mutual trust 'through new monitoring of Member States' asylum and reception systems and through the ability for the Commission to issue recommendations with assistance measures' ${ }^{39}$ A seminal future challenge will be the inherent underlying tension between the expanding operational and supervision mandates of EU agencies..$^{40}$ Namely, the agencies will be called on to play a double, and at times contradictory role: implementing jointly, while simultaneously supervising implementation.

Next, the Communication identifies a 'leading role' for FRONTEX in the EU common system on returns (p. 8). The Commission goes as far as to state that ' $[\mathrm{i}] \mathrm{t}$ should be a priority for Frontex to become the operational arm of EU return policy'. ${ }^{41}$ This is linked with the deployment of the agency's standing corps. ${ }^{42}$ According to the November 2019 version of its Regulation, it is expected that by 2027 FRONTEX would have a total of 10.000 operational staff, comprised of both statutory staff, and staff made available through Member States for long and short term deployments. ${ }^{43}$ Achieving this level of operational staff is recognised by the Commission as 'essential for the necessary capability to react quickly and sufficiently'. ${ }^{44}$ Return is a key area where operational staff will be involved.

A final area from the Communication concerns partnerships with third countries. The Commission envisages 'a much deeper involvement of EU agencies' to support the new partnerships. ${ }^{45}$ It goes as far as to say that FRONTEX's 'enhanced scope of action should now be used to make cooperation with partners operational'. ${ }^{46}$ In what concerns the Western Balkans FRONTEX is to 'to work together with national border guards on the territory of a partner country'. ${ }^{47}$ Reference is clearly made to joint implementation patterns in those countries. EASO is not left out either, however the Commission falls short of mentioning joint implementation patterns

39 Ibid, 6.

40 Tsourdi, 'Beyond the migration crisis: the evolving role of EU agencies in the administrative governance of the asylum and external border control policies' ( $\mathrm{n}$ 17), 193-194.

41 Pact Communication (n 1), 8.

42 Ibid.

432019 EBCG Regulation (n 5).

44 Pact Communication (n 1), 12.

45 Ibid, 20.

46 Ibid, 21.

47 Ibid. 
in the assessment of asylum claims. Rather it refers to capacity building and operational support, as well as support on refugee resettlement from third countries to the EU. 48

\section{b) The Pact Legal Instruments: No Adequate Reflection of Policy Ambition}

These programmatic statements are not fully reflected in the legal instruments that make up the Pact. It is impossible to examine all Pact instruments exhaustively in this contribution. Instead, I will draw characteristic examples to illustrate my points.

\section{aa) Border Procedure: Unsatisfactory Embedding of EU Agencies' Existing Roles and Current Administrative Realities}

The border procedure established by the Amended Proposal for an Asylum Procedures Regulation ${ }^{49}$ is an illustrative example of unsatisfactory embedding EU agencies' existing roles and current administrative realities. The intricacies of the procedure itself are analysed in this publication by Jens Vedsted-Hansen. ${ }^{50}$ Overall, through this procedure the Commission seeks to create 'a seamless link between all stages of the migration procedure, from a new pre-entry phase to the outcome of an asylum application'. ${ }^{51}$ The pre-entry phase includes screening regulated by a different instrument, ${ }^{52}$ analysed in this publication by Lyra Jakuleviciene. ${ }^{53}$ For those channelled based on this initial screening to an asylum procedure, a decision will be made as to whether their application 'should be assessed without authorising the applicant's entry into the Member State's territory in an asylum border procedure or in a normal asylum procedure'. ${ }^{54}$ If channelled to an asylum border procedure and found not to be in need

48 Ibid.

49 Amended Proposal for an Asylum Procedures Regulation (n 3).

50 See Jens Vedsted-Hansen's chapter in this book.

51 Amended Proposal for an Asylum Procedures Regulation (n 3), Explanatory Memorandum, 3.

52 Screening Regulation Proposal (n 2).

53 See Lyra Jakuleviciene's contribution in this volume.

54 Amended Proposal for an Asylum Procedures Regulation (n 3), Explanatory Memorandum, 4. 
of protection, failed applicants would then be directed to a return border procedure.

The border procedure is not unknown to national asylum systems. However, it is currently not obligatory, nor is it regulated by such detail in EU law. Rather, the possibility exists under EU law for Member States to introduce such a procedure to be framed by national law. This is a possibility that some Member States have taken up. EU agencies, and specifically EASO, have come to play pivotal roles in the application of current variants of border and accelerated procedures. The agency has been key in the operationalisation of the hotspot approach to migration management ${ }^{55}$ in Greece. Greek national law in 2016 introduced an accelerated border asylum procedure, addressing also the situation at hotspots. ${ }^{56}$ Consecutive amendments of Greek national law established increasing levels of EASO involvement in the processing of asylum applications in admissibility and, later, the merits of applications. ${ }^{57}$ While the final decision rests with the Greek Asylum Service, EASO experts emit a non-binding advisory opinion, making these processes a peculiar type of mixed proceedings regulated only by national law, with the involvement of both the EU and national levels in asylum decision-making. EASO's implication in processing in Greece is numerically significant. For example, EASO conducted 8,958 interviews in the fast-track border procedure during 2018. ${ }^{58}$ During the first half of 2019, EASO conducted 2,955 interviews in the fast-track border procedure, ${ }^{59}$ mainly covering applicants from Afghanistan, Palestine, Iraq, Syria and Cameroon.

Given these factual realities and the pivotal role played by EASO in existing national variants of border procedures, the proposed amended Asylum Procedures Regulation is surprisingly silent on the role of EU agencies in general and, of EASO specifically. The Commission announces that through its proposal, 'consistency is ensured' with the provisional

55 Katrien Luyten and Anita Orav, Hotspots at EU external borders: State of play (European Parliament, PE 652.090, September 2020).

56 See Law 4375/2016, art 60(4).

57 I am referring to Law 4540/2018 of May 22, 2018, Official Gazette of the Greek Government, Series A, Issue No. 91, 8005 et seq., art 28(7), and Law 4346/2019 of Nov. 1, 2019, Official Gazette of the Greek Government, Series A, Issue 169, 4827 ('Greek International Protection Act', art 76(1) - personal interviews on admissibility, art 76(2) - personal interviews on the merits of the case and art 90 border procedures).

58 Minos Mouzourakis, The Role of EASO Operations in National Asylum Systems (ECRE 2019) 11.

59 Ibid, 12. 
political agreements already reached on most elements of the EUAA. ${ }^{60}$ Again, in the Explanatory Memorandum of the proposal in a paragraph titled 'budgetary implications' the Commission states that 'within their respective mandates', EASO and FRONTEX can support Member States with staff for operationalising the border procedure. ${ }^{61}$ This of course could include involvement in processing applications through joint implementation patterns, an element that is partially included in the new enhanced mandate of the EUAA. Thereafter, the proposal refers to EASO's material, as part of its quality initiatives, on operational standards and indicators for asylum procedures. ${ }^{62} \mathrm{~A}$ recital also refers to EASO's guidance notes, as part of the material to be taken into account in ascertaining which applicants fall under the border procedure. ${ }^{63}$

These passing references to the possibility of EASO staff supporting border procedures do not do justice to current administrative realities. EASO is in fact involved in the assessment of thousands of applications in Greece, mainly as part of the country's border procedure. New, enhanced, obligations to conduct such type of processing will only increase the needs of border Member States for operational support. While the instrument does not negate the involvement of EASO within the remits of its mandate in asylum processing, it does not explicitly reflect or regulate the procedural implications of EU-coordinated involvement either. And yet, the EU Ombudsman has already been called twice to scrutinize potential violations of applicants' procedural rights in Greece, due to EASO involvement. ${ }^{64}$ These complaints reveal the procedural complexities and need for a broader rethink of EU procedural law and the establishment of the req-

60 Amended Proposal for an Asylum Procedures Regulation (n 3), Explanatory Memorandum, 6.

61 Ibid, 8.

62 Ibid.

63 Ibid, recital 39(a).

64 See Decision of European Ombudsman in Case 735/2017/MDC on the European Asylum Support Office's (EASO) Involvement in the Decision-Making Process Concerning Admissibility of Applications for International Protection Submitted in the Greek Hotspots, in particular Shortcomings in Admissibility Interviews (5 July 2018) <www.ombudsman.europa.eu/en/decision/en/9871 $1>$ accessed 1 December 2021; and Decision of the European Ombudsman in Case 1139/2018/MDC on the Conduct of Experts in Interviews with Asylum Seekers Organised by the European Asylum Support Office (30 September 2019) $<$ www.ombudsman.europa.eu/en/decision/en/119726 $>$ accessed 1 December 2021. 
uisite accountability arrangements. ${ }^{65}$ Similar observations regarding lack of reflection on EU agencies' involvement can be made about the new screening procedure. ${ }^{66}$

\section{bb) Return Sponsorships: Embedding the Two-Track Approach to Administrative Cooperation}

Return sponsorships are an illustrative example of the Pact's embedding of the two-track approach to administrative cooperation. They are one of the solidarity tools envisaged by the Asylum and Migration Management Regulation. ${ }^{67}$ Through a return sponsorship a Member State (say Hungary) commits to support another Member State which faces 'migratory pressure' (say Greece) in carrying out the necessary activities to return irregularly staying third-country nationals. While the individuals are present on the territory of Greece, it remains responsible for carrying out the return. However, if return has not taken place after 8 months $(4$ months in situations of crisis), ${ }^{68}$ Hungary becomes responsible for transferring the migrants in an irregular situation and should relocate them to its territory. ${ }^{69}$

The instrument recognises that return sponsorship is part of the common EU system of returns, which also includes operational support through FRONTEX. ${ }^{70}$ Measures to support return include providing counselling; using 'the national programme and resources for providing logistical, financial and other material or in-kind assistance' to those willing to depart voluntarily; leading or supporting the policy dialogue and exchanges with the authorities of third countries for the purpose of facilitating readmission; contacting the third country authorities to verify identity and obtain a valid travel document; and organising on behalf of the benefitting Member State the practical arrangements for the enforcement

65 See Tsourdi, 'Holding the European Asylum Support Office Accountable for its role in Asylum Decision-Making: Mission Impossible' (n 24).

66 See Screening Regulation Proposal (n 2), Explanatory Memorandum, 3, recital 21, and art 6(7).

67 See analysis in Olivia Sundberg Diez, Florian Trauner and Marie De Somer, 'Return Sponsorships in the EU's New Pact on Migration and Asylum: High Stakes, Low Gains' (2021) 23 European Journal of Migration and Law 219-244.

68 Proposal for a Regulation of the European Parliament and of the Council addressing situations of crisis and force majeure in the field of migration and asylum, $\operatorname{COM}(2020) 613$ of 23 September 2020 ('Crisis Regulation Proposal'), recital 10.

69 Asylum and Migration Management Regulation (n 4), art 55(2).

70 Ibid, recital 27. 
of return, such as charter or scheduled flights or other means of transport to the third country of return. ${ }^{71}$

The Commission affirms that these activities are 'additional to the ones carried out by the European Border and Coast Guard Agency (EBCGA) by virtue of its mandate and notably include measures that the Agency cannot implement (e.g. offering diplomatic support to the benefitting Member State in relations with third countries)' ${ }^{72}$ Nonetheless, when one scrutinizes the measures that Member States are to undertake in the framework of a return sponsorship it becomes apparent that they are not all additional to the activities FRONTEX undertakes. For example, organising the practical arrangements for the enforcement of return is an action that also FRONTEX undertakes as part of its operational role on returns. Therefore, there will now officially be two tracks on administrative cooperation on returns: an institutionalised one, i.e. through FRONTEX, and a second track which, in essence, will consist of several bilateral co-operations between a 'benefiting Member State' and other Member States that will activate themselves in 'sponsoring' returns.

A policy choice was clearly made: instead of streamlining all operational support on return through FRONTEX, the Pact envisages a parallel track, that of bilateral transnational co-operation on implementing return. It seems that Member States were not yet fully prepared to make FRONTEX the 'operational arm' of the EU return policy after all. It will be one of the actors that will be active in this area. The other actors will be Member States through their administrations.

Institutionalised administrative integration through EU agencies is not inherently negative or positive. I already outlined the accountability and fundamental rights challenges that have emerged through the increased operational powers of EU agencies. However, bilateral administrative cooperation in this area is likely to present even more problems. It is unlikely to be efficient as it will not allow for the creation of economies of scale. It will create additional administrative burdens for the 'benefitting' Member state that instead of one interface will have to collaborate with several Member State authorities that will be acting, understandably, in an uncoordinated manner.

In addition, operational support under this framework will not be covered by the enhanced fundamental rights protection layer that has been developed by FRONTEX including, inter alia, a fundamental rights officer,

71 Ibid, art 55(4)(a-d).

72 Ibid, Explanatory Memorandum, 2, emphasis added. 
an individual complaints mechanism, and fundamental rights monitors. ${ }^{73}$ This framework has been put in place specifically to address fundamental rights violations in the framework of operational activities of the agency. Put plainly, a migrant under a return obligation in the territory of Greece, whose return is sponsored by Hungary under a bilateral cooperation framework, cannot make use of the FRONTEX individual complaints mechanism regarding a potential violation by a Hungarian agent. It is certain that these mechanisms are not flawless as the most recent allegations on the role of FRONTEX in pushbacks in Greece once again highlight. ${ }^{74}$ But the complete absence of these novel human rights mechanisms in an environment of transnational administrative cooperation which dilutes accountability and liability will be even worse. Monitoring foreseen by the Commission as part of the Asylum and Migration Management Regulation ${ }^{75}$ might be able to reveal potential violations, especially where they are widespread, but will not be linked with an 'access to justice' component for individuals.

\section{Concluding Remarks}

The New Pact was expected to breathe new life into EU's asylum, migration, and external border control policies. There is little innovative thinking though in what concerns the role of EU agencies and opportunities presented by administrative integration. The programmatic declarations of the Pact Communication endorse the status quo in what concerns the role of EU agencies. When it comes to EASO's mandate, the newly adopted agreement on an EUAA only partly reflects current operational realities. This means the agency's mandate will continue to be out of tune with the administrative reality on the ground. For the rest, its monitoring-like functions have been locked into the negotiating impasse on solidarity.

Unlike the Pact Communication, the Pact legal instruments do not fully embed, or regulate, existing de jure and de facto developments, such as joint implementation patterns. The Pact's 'fresh' approach is to provide renewed attention to the other track of administrative co-operation, which

732019 EBCG Regulation, arts 108-111.

74 See, e.g. Giorgos Christides and others, 'Frontex in illegale Pushbacks von Flüchtlingen verwickelt' (Der Spiegel, 23 October 2020) <www.spiegel.de/ausla nd/fluechtlinge-frontex-in-griechenland-in-illegale-pushbacks-verwickelt-a-000000 00-0002-0001-0000-000173654787> accessed 1 December 2021.

75 Asylum and Migration Management Regulation (n 4), art 6. 
is bilateral and multilateral transnational administrative co-operation between Member States. This method is not inherently negative. However, it is unlikely to prove efficient in policies which essentially seek to provide regional public goods, such as asylum provision, or safeguarding EU's external borders in respect of fundamental rights. It also seems capable of jeopardizing migrants' fundamental rights even further.

Member State support for agency involvement to better respond to functional pressures and the unmet interstate solidarity imperative might have acted as the precursor of more radical shifts in the implementation modes of these policies. ${ }^{76}$ At the current juncture though, it seems that Member States and the Commission had little appetite for such a policy direction. Not much is new under the sun then, other than the Pact's ambivalence towards administrative integration.

76 Evangelia (Lilian) Tsourdi, 'EU Agencies' in Philippe De Bruycker, Marie De Somer and Jean-Luis De Brouwer (eds), From Tampere 20 to Tampere 2.0. Towards a new European consensus on migration (EPC 2019) 27-38. 